\title{
Australian Journal of Crop Science \\ How are germination performance and seedling establishment under abiotic stress improved by seed priming? A review
}

\author{
Alexandre Bosco de Oliveira ${ }^{1 *}$, Enéas Gomes-Filho ${ }^{2}$ \\ ${ }^{1}$ Federal University of Ceará, Department of Crop Science, Center of Agricultural Sciences, Av. Mister Hull, \\ 2977, zip code 60356-001, Fortaleza, CE, Brazil \\ ${ }^{2}$ Federal University of Ceará, Department of Biochemistry and Molecular Biology, National Institute of Science \\ and Technology in Salinity (INCTSal), post office box 6039, zip code 60455-970, Fortaleza, CE, Brazil
}

*Corresponding author: aleufc@gmail.com

\begin{abstract}
Seed priming, also called osmoconditioning, is one of the most promising treatments for reducing the time needed between sowing and seedling emergence. In addition, this treatment has also been associated with increases in seed tolerance to adverse conditions during seed germination and seedling establishment. Thus, this review examines the major changes seen in abiotically stressed plants as a result of seed priming treatments, in particular physiological and biochemical changes promoted by seed priming. Many studies cited in this review have reported improvements in seed physiological quality and seedling vigour when using seed priming under abiotic stress conditions. These features have been related to the repair and build-up of nucleic acids, increases in the synthesis of proteins, osmotic adjustment mechanisms, the repair of membranes and reduced lipid peroxidation, resulting from enhanced antioxidative activities. However, further studies are necessary to explain how physiological and biochemical changes caused by seed priming improve the plant's adaptations to stressful environmental conditions.
\end{abstract}

Keywords: osmoconditioning, seeds physiological quality, performance improvement, stressful conditions, physiological and biochemical mechanisms.

\section{Introduction}

Low quality seeds frequently require more time for germination and seedling emergence. This makes the seedlings more sensitive to adverse climates, reducing the final percentage of seedling emergence and normally resulting in irregular emergence. Therefore, many studies have been carried out looking for ways to provide faster seedling emergence in the field and tolerance to adverse conditions during germination. One of the most promising treatments is seed priming, commonly known as osmoconditioning, which consists of the controlled hydration of seeds to facilitate the initial germination process without the occurrence of root protrusion (McDonald, 2000). The basis of all pre-sowing is to hydrate the seeds under controlled conditions so that they become physiologically active and able to initiate repair mechanisms and detoxify the system (Devaraju et al., 2011). In the literature, we can find various studies using different types of salts in pre-sowing soaking treatments with seeds from various crops. These studies aim for either, better established seedlings or better plant stand and yield under varied environmental conditions (Jisha et al., 2013; Ibrahim, 2016).

Since the discovery of seed priming in plants in the 1970s (Heydecker et al., 1975), the phenomenon has been demonstrated in different plant species, especially under abiotic stress conditions. Hence, priming appears to be a common feature of plant immune systems' that offers protection against a wide spectrum of environmental stresses (Ton et al., 2009). Improvements in germination performance under abiotic stress conditions have been reported in the literature as a direct response of seed priming, like those observed by Oliveira et al. (2010), who showed that priming increased the maximum tolerance to salt stress. Pereira et al. (2009) ascertained that treating carrot seeds in PEG-6000 solutions increased the emergence of seedlings in the field and the performance in sub and supra-optimal temperatures, while Patanè et al. (2009) found that osmoconditioning of sweet sorghum seeds mitigated the harmful effects caused by salt and thermal stress during germination and root growth. As mentioned previously, seed priming techniques use different substances and methodologies. Hence, the name of the treatment may vary according to the protocol followed. These treatments can be named hydropriming, hardening, osmoconditioning, osmohardening, matricopriming and hormonal priming. Hydropriming is the simplest approach to hydrating seeds and minimises the use of chemicals. However, if seeds are not accurately hydrated, hydration rates cannot be precisely controlled (Farahani et al., 2011). Therefore, this is one of the reasons why seed priming has been performed not only by soaking simply in water but also in a solution of salts, hormones, osmoprotectants, matric strain-producing materials and other nonconventional means. One of the most common substances used is the polyethylene glycol 6000, which is widely used in these kinds of experiments.

Seed priming treatments have been used to accelerate the emergence of roots and shoots, produce more vigorous plants and provide better drought tolerance in many field crops (Kamran et al., 2009; Yagmur and Kaydan, 2010; Iqbal and 
Ashraf, 2013). In addition, the beneficial effects of seed priming have assured better germination and seed emergence, as well as seedling establishment, in many crops, particularly under abiotic stress, as reported by Patanè et al. (2009). These authors showed that osmoconditioning of sweet sorghum seeds mitigated the harmful effects caused by salt and thermal stress during germination and radicle growth. Similarly, Oliveira et al. (2010) showed improvements in water uptake and the percentage and velocity of sorghum seed germination. This behaviour has been associated with the repair and build-up of nucleic acids, increases in the synthesis of proteins and the repair of membranes (McDonald, 2000).

Seed priming also enhances the activities of antioxidative enzymes in treated seeds (Espanany et al., 2016). Therefore, the improved seed quality promoted by seed priming has been associated with a reduction in lipid peroxidation, resulting from enhanced antioxidative activity (Chiu et al., 2006). In addition to the beneficial effects cited previously, recent progress made on molecular aspects of seed priming has related this treatment with the accumulation of dormant mitogen-activated protein kinases, chromatin modifications and alterations of primary metabolism (Conrath, 2011).

Here in this review, we discuss the potential of seed priming treatments for improving seed and seedling performance under abiotic stress conditions. Therefore, after this general review, we will present the major physiological and biochemical changes induced by environmental stresses and seed priming.

\section{Seed ageing and salinity induces membrane damage through oxidative stress}

Biochemical and physiological deterioration during seed aging has been studied mostly under accelerated aging conditions using high temperatures and high seed water content. Some studies indicate that membrane lipid peroxidation is one of the major causes of seed aging under accelerated aging conditions (Oliveira et al., 2011a). However, plants contain numerous antioxidant compounds, both enzymatic and non-enzymatic, which act to prevent oxidative damage by scavenging free radicals before they attack membranes or other seed components (Bhaskaran and Panneerselvam, 2013). Some protective mechanisms involving free radical and peroxide scavenging enzymes, such as catalase (CAT), guaiacol peroxidase (POX), ascorbate peroxidase (APX) and superoxide dismutase (SOD), have been evaluated within the mechanism of seed aging (Pukacka and Ratajczak, 2007; Espanany et al., 2016). Another major constraint to seed germination and seedling establishment is soil salinity, which is a limiting factor on crop production in arid and semi arid regions of the world. Soil salinity may affect the germination of seeds and seedling establishment either by creating an osmotic potential external to the seed and roots, preventing water uptake, or through the toxic effects of $\mathrm{Na}^{+}$and $\mathrm{Cl}^{-}$ions on the germinating of the seed and plant growth (Iqbal and Ashraf, 2013). In addition to ionic and osmotic components, salt stress, e.g. accelerated aging of seeds, also leads to oxidative stress through an increase in reactive oxygen species (ROS), such as superoxide $\left(\mathrm{O}_{2}{ }^{-}\right)$, hydrogen peroxide $\left(\mathrm{H}_{2} \mathrm{O}_{2}\right)$ and hydroxyl radicals $\left(\mathrm{OH}^{*}\right)$ (Oliveira et al., 2011a; Bhaskaran and Panneerselvam, 2013).

Water uptake and germination improvement in abiotically stressed seeds and contradictory effects under multiple stress conditions
Many authors have observed improvement in the physiological quality of seeds when they are under specific stress conditions, such as sub or supra-optimal temperatures, water deficits or high salinity in the medium (Bejandi et al., 2009; Patanè et al., 2009; Pereira et al., 2009; Jisha et al., 2013). Oliveira et al. (2010) evaluated water uptake, germination and the initial growth of sorghum seedlings from artificially aged and osmoconditioned seeds under conditions of salt stress. The seeds water uptake was directly related to water availability, the matric potential of the substrate, the osmotic potential of the solution that moistens the substrate and the temperature and intrinsic characteristics of the seed. In this experiment, priming promoted an increase in wateruptake rate only in seeds with greater vigour, in other words, those not subjected to accelerated aging. Increases in the water-uptake rates might result from an accumulation of solutes from the onset of seed metabolism during priming, resulting in greater seed swelling when rehydrated (McDonald, 2000). Increases in seedling growth correlated with higher water uptake by primed seeds, resulting in higher seedling growth (Yagmur and Kaydan, 2010). Similarly, the results obtained by Oliveira et al. (2010) in sorghum seeds subjected to salt stress confirmed that the effects of seed priming were easily notable on seedling growth, especially when the environment was unfavourable. Afzal et al. (2008) subjected maize seeds to hydropriming, hormonal priming with $100 \mathrm{mg} \mathrm{L}^{-1}$ gibberellic acid $\left(\mathrm{GA}_{3}\right)$ or indole-3-acetic acid (IAA) solutions and halopriming with $50 \mathrm{mM} \mathrm{CaCl}_{2}$ or $50 \mathrm{mg} \mathrm{L}^{-1}$ ascorbate (ASA) for $24 \mathrm{~h}$. Seed priming enhanced the germination of spring maize under cool conditions, with a better performance in seeds subjected to $\mathrm{CaCl}_{2}$ or ASA. According to these authors this could be associated to the effect of higher reducing and total sugars, as well as higher $\alpha$ amylase activity. Li et al. (2011) conducted laboratory experiments on freshly harvested pyrethrum (Tanacetum cinerariifolium) seeds to investigate the effects of light (influenced by the seeding method) and seed hydropriming on germination and shoot and root growth at $25{ }^{\circ} \mathrm{C}$. The responses of hydroprimed and unprimed seeds to salt and drought stress were determined at osmotic potentials of 0 (distilled water), $-0.3,-0.6,-0.9,-1.2 \mathrm{MPa}$ in $\mathrm{NaCl}$ and PEG-6000. In this study, the researchers showed that hydropriming shortened the delay of mean germination time for all osmotic potentials and improved the germination percentage in distilled water (from $52 \%$ to $59 \%$ ) and resistance to salt stress, with nearly double germination (from $16 \%$ to $29 \%$ ) at the highest salt concentration. On the other hand, Oliveira et al. (2010) reported that in seeds with less vigour (artificially aged) subjected to salt stress, those not subjected to priming showed a higher water-uptake rate than those that were osmoconditioned. This greater uptake of water may be related to the fact that aged and deteriorated seeds were more sensitive to soaking damage, as the cell membranes were weakened, reducing their integrity and making them more susceptible to rapid water movement into the cell (Sveinsdóttir et al., 2009).

\section{Osmotic adjustment in $\mathrm{NaCl}$-stressed seedlings induced by seed priming}

Plants usually develop mechanisms that allow the maintenance of growth under salt-stress conditions; these mechanisms tend to limit salt absorption into the plant in order to avoid toxic ion concentrations in the cytosol (Witzel et al., 2010). In general, salt-tolerant plants perform osmotic adjustments through the accumulation of osmotically active 


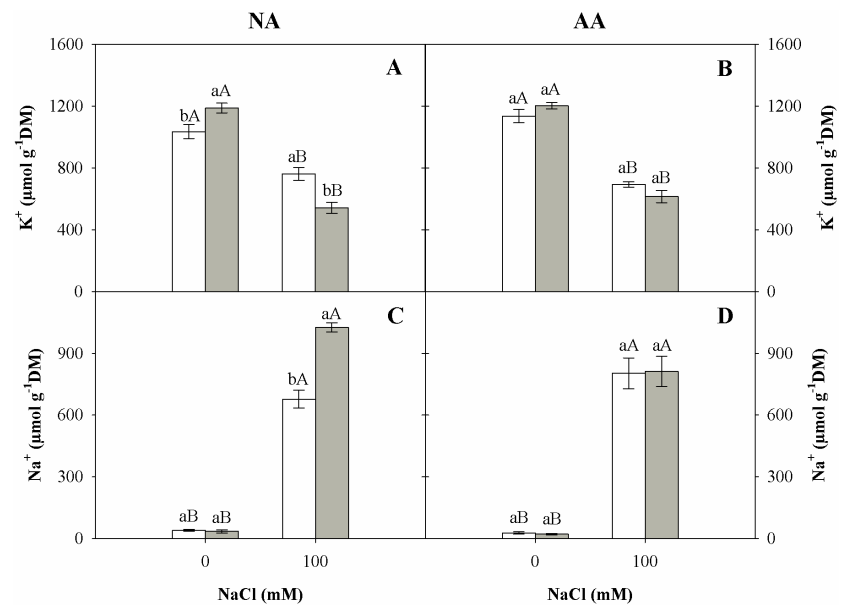

Fig 1. The potassium $\left(\mathrm{K}^{+}, \mathrm{A}\right.$ and $\left.\mathrm{B}\right)$ and sodium $\left(\mathrm{Na}^{+}, \mathrm{C}\right.$ and $\left.\mathrm{D}\right)$ content in sorghum seedling shoots from non-aged (NA) or artificially aged (AA) seeds and seeds subjected to $(\square)$ or not subjected to $(\square)$ seed priming under different salt levels.

The columns with distinct colours and equal lowercase letters for seedlings under the same $\mathrm{NaCl}$ levels, and the columns with the same capital letters for seedlings under different $\mathrm{NaCl}$ levels, did not differ between treatments using a Tukey's test at $5 \%$ of probability. The vertical bars represent the standard error (From Oliveira et al, 2011a).

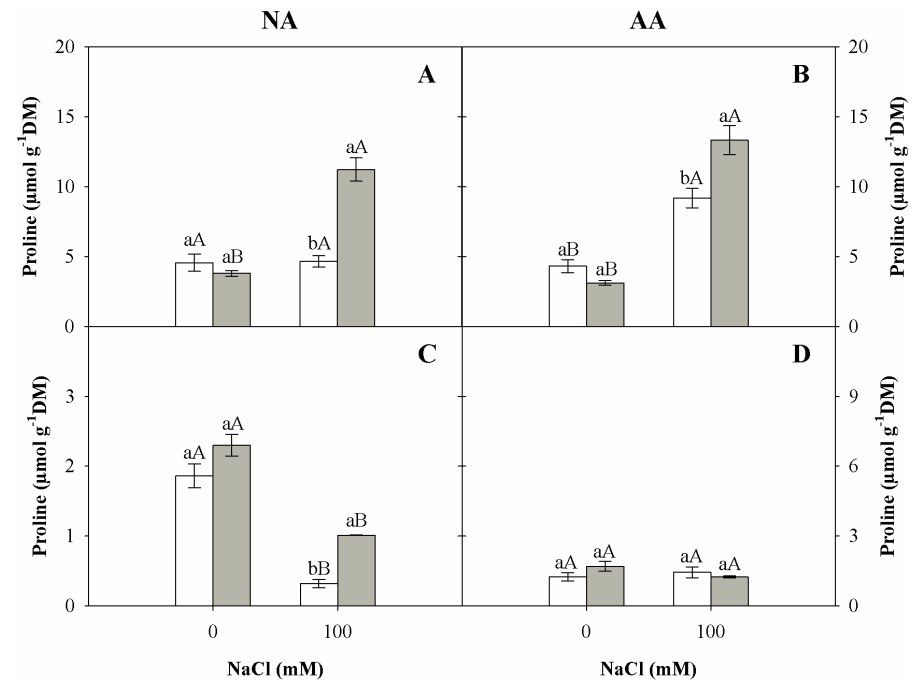

Fig 2. The proline content in shoots (A and B) and roots (C and D) of sorghum seedlings from non-aged (NA) or artificially aged (AA) seeds and subjected to $(\square)$ or not subjected to $(\square)$ seed priming under different salt levels.

The columns with distinct colours and equal lowercase letters for seedlings under the same $\mathrm{NaCl}$ levels, and the columns with the same capital letters for seedlings under different $\mathrm{NaCl}$ levels, did not differ between treatments using a Tukey's test at $5 \%$ of probability. The vertical bars represent the standard error (From Oliveira et al, 2011a).

solutes, such as ions, in the vacuole and organic solutes, which allow water uptake, cell enlargement and plant growth under salinity (Yamaguchi and Blumwald, 2005).

The osmolytes that usually participate in osmotic adjustment vary between species and plant developmental stage and consist of sugars (glucose and fructose), alcohols (glycerol) and amino quaternary compounds (glycine betaine and proline) (Liu et al., 2015). As a result, some of these substances might even be useful in seed priming treatments for abiotic stress alleviation. For instance, Zhang and Rue (2012) showed that seed priming with glycine betaine improved the osmotic and salinity tolerance of turfgrasses, resulting in enhanced seed germination and seedling growth under salinity stress. Oliveira et al. (2011b) verified that the osmopriming of low physiological quality sorghum seeds (non-aged) reduced the negative effects of salinity $(100 \mathrm{mM}$ $\mathrm{NaCl}$ ) on seedling growth. They argue that $\mathrm{Na}^{+}$and $\mathrm{Cl}^{-}$ accumulation in the shoots of $\mathrm{NaCl}$-stressed sorghum seedlings from primed seeds indicates an osmotic adjustment induced by seed priming, which was efficient in reducing the osmotic stress caused by salinity (Fig 1). Furthermore, these authors confirmed that proline was the main contributing organic solute in the osmoregulation of seedling shoots subjected to salinity and that its levels increased due to seed priming (Fig 2). Thus, the observed results in the literature suggest that changes in inorganic and organic solute concentrations in both the shoot and roots could be induced by seed priming as a function of the salt stress tolerance caused by this treatment, although the changes in these organs are poorly related to each other. Jafar et al. (2011) soaked wheat seeds in aerated solutions of ascorbate, salicylic acid, kinetin and $\mathrm{CaCl}_{2}$ for $12 \mathrm{~h}$ and showed that as an index of salinity tolerance, the seed priming treatments also improved the leaf $\mathrm{K}^{+}$content, simultaneously decreasing $\mathrm{Na}^{+}$ concentration, with osmopriming being the best treatment. Similarly, this study reported maximum total phenolic 
content, total soluble proteins (TSP) and $\alpha$-amylase and protease activity with the osmoprimed treatment (with $\mathrm{CaCl}_{2}$ ) of the seeds followed by ascorbate priming. According to this study, economic analysis also indicated that osmopriming is more viable, with maximum net returns and benefit-to-cost ratios.

\section{Activation of the antioxidant enzymatic system by seed priming}

Seed priming stimulates the pre-germination metabolic processes and makes the seed ready for radicle protrusion. Thus, it increases the activity of the antioxidant system and the repair of membranes (Ibrahim, 2016).

The lowest lipid peroxidation levels in abiotic-stressed seedlings from osmoconditioned seeds can be related to seed priming's capacity to act as a repairer of seed deterioration resulting from lipid peroxidation, which was reported previously by McDonald (2000). Chiu et al. (2006) observed that this improvement might be associated with the conversion of lipids into carbohydrates and the antioxidant activity promoted by priming through increased activity of enzymes, such as isocitrate lyase (IL) and malate synthase (MS) in the first process, and SOD, CAT, APX, peroxidase (PO) and glutathione reductase (GR) in the second process. Oliveira et al. (2011a) evaluated the growth, lipid peroxidation and activity of antioxidative enzymes in sorghum seedlings grown under salt stress from artificially aged and primed seeds. They showed that priming of low physiological quality seeds (aged seeds) reduced the negative effects of salinity $(100 \mathrm{mM} \mathrm{NaCl})$ on seedling growth. The results obtained by these authors suggest that osmoconditioning induced an increase in catalase (CAT) and guaiacol peroxidase (GPX) activity and these enzymes protected the seedlings against oxidative damage caused by seed accelerated aging and the salinity of the nutrient solutions.

In a study carried out by Kibinza et al. (2011), the importance of catalase in oxidation protection during accelerated ageing and repair during subsequent priming treatment was investigated in sunflower (Helianthus annuus L.) seeds. The inhibition of catalase by the addition of aminotriazole during the priming treatment reduced seed repair, indicating that catalase plays a key role in protection and repair systems during ageing, which was associated with $\mathrm{H}_{2} \mathrm{O}_{2}$ accumulation, as shown experimentally by the authors using biochemical quantification and $\mathrm{CeCl}_{3}$ staining. They verified that catalase activity decreased at the level of gene expression, protein content and affinity. In addition, priming induced catalase synthesis by activating the expression and translation of the enzyme.

It is important to remember that CAT is an enzyme of great relevance in protecting plants against reactive oxygen species. This is one of the main enzymes that removes $\mathrm{H}_{2} \mathrm{O}_{2}$, which may lead to the formation of hydroxyl radicals ${ }^{\circ} \mathrm{OH}$ ), causing lipid peroxidation and cell membrane peroxidation, thus damaging plant growth (Bhaskaran and Panneerselvam, 2013).

\section{Pre-sowing seed treatment using plant growth regulators and hormones}

There are various strategies that can be employed these days to mitigate the adverse effects of salinity stress. Among them, pre-sowing seed treatments with plant growth regulators has gained much attention for being one of the most economical approaches of growing crops in salt affected soils (Kamran et al., 2009; Pérez-García, 2009). However, other studies have shown that various priming agents have varying responses according to the kind of abiotic stress and crop species. Presowing seed treatments with triacontanol (TRIA), for example, did not alter the studied attributes by Perveen et al. (2011). One exception observed by the authors was under non-saline conditions, where TRIA application increased POD activity significantly in both cultivars. Seed priming with hormones has been shown to be an efficient method for increasing seed vigour, as well as seedling growth under stressful conditions. These responses have been associated with the activation of antioxidant systems in a range of crops (Carvalho et al., 2011). Azooz (2009), working with Vicia $f a b a$, reported improvement in salinity tolerance due to the application of salicylic acid during seed priming, which was associated with enhanced CAT, ascorbate peroxidase (APX), POD and glutathione reductase (GR) activity.

In another study, Eisvand et al. (2010) verified that Agropyron elongatum seeds primed with gibberellin (GA) and abscisic acid (ABA) exhibited induced CAT and SOD activity under drought conditions when compared to unprimed seeds. On the other hand, the results described by Carvalho et al. (2011) showed that hormonal priming with methyl jasmonate, salicylic acid or CEPA (chloroethylphosphonic acid), an ethylene (ET) releaser, does not induce the antioxidant activity of superoxide dismutase, catalase, ascorbate peroxidase or glutathione reductase in maize seedlings subjected to salt stress.

Iqbal and Ashraf (2013) showed that treatment with $\mathrm{GA}_{3}$ (150 mg L $\left.{ }^{-1}\right)$ decreased $\mathrm{Na}^{+}$concentrations in both shoots and roots and increased $\mathrm{Ca}^{2+}$ and $\mathrm{K}^{+}$concentrations in the roots of two spring wheat (Triticum aestivum L.) cultivars, namely MH-97 (salt intolerant) and Inqlab-91 (salt tolerant). According to these authors, GA3-priming induced increases in grain yield, which they attributed to $\mathrm{GA}_{3}$-priming-induced modulation in ion uptake and partitioning (within shoots and roots) and hormone homeostasis under saline conditions.

\section{Conclusions}

Although there has been an immense amount of recent research investigating abiotic stress enhancements associated with seed priming, few studies have addressed combined stresses, such as seed aging and salinity. The beneficial effects of priming have also been proven in germination and the emergence of seeds and seedlings in many crops, particularly under abiotic stress. The improvements in the physiological quality of seeds and seedling vigour by seed priming under abiotic stress conditions has been related to the repair and build-up of nucleic acids, the increased synthesis of proteins, osmotic adjustment mechanisms, the repair of membranes and reduced lipid peroxidation, resulting from enhanced antioxidative activity. Although many improvements and new discoveries have been related in the literature, further studies are necessary to better explain how the physiological and biochemical changes caused by seed priming improves plants' adaptations to stressful environmental conditions.

\section{Acknowledgements}

The authors would like to thank the National Institute of Science and Technology in Salinity (INCTSal) and the Brazilian National Council for Scientific and Technological Development for their financial support. 


\section{References}

Afzal I.; Basra SMA, Shahid M, Farooq M, Saleem M (2008) Priming enhances germination of spring maize (Zea mays L.) under cool conditions. Seed Sci Technol. 36:497-503.

Azooz MM (2009) Salt stress mitigation by seed priming with salicylic acid in two faba bean genotypes differing in salt tolerance. Int J Agric and Biol. 11:343-350.

Bejandi TK, Sedghi M, Sharifi RS, Namvar A, Molai P (2009) Seed priming and sulfur effects on soybean cell membrane stability and yield in saline soil. Pesq Agrop Bras. 44:11141117.

Bhaskaran J, Panneerselvam R (2013) Accelerated reactive oxygen scavenging system and membrane integrity of two panicum species varying in salt tolerance. Cell Biochem Biophys 67:885-892.

Carvalho RF, Piotto FA, Schmidt D, Peters LP, Monteiro CC, Azevedo RA (2011) Seed priming with hormones does not alleviate induced oxidative stress in maize seedlings subjected to salt stress. Sci Agric. 68:598-602.

Chiu KY, Chuang SJ, Sung JM (2006) Both anti-oxidation and lipid-carbohydrate conversion enhancements are involved in priming-improved emergence of Echinacea purpurea seeds that differ in size. Sci Hortic. 108:220-226.

Conrath U (2011) Molecular aspects of defence priming. Tr in Plant Sci. 16:524-531

Devaraju PJ Nagamani S, Gowda RV, Yogeesha HS, Gowda R, Nagaraju KS, Shashidhara N (2011) Effect of chemo priming on plant growth and bulb yield in onion. Int $\mathrm{J}$ of Agric Env and Biotech. 4:121-123.

Eisvand HR, Tavakkol-Afshari R, Sharifzadeh F, Maddah Arefi H, Hesamzadeh Hejazi SM (2010) Effects of hormonal priming and drought stress on activity and isozyme profiles of antioxidant enzymes in deteriorated seed of tall wheatgrass (Agropyron elongatum Host). Seed Sci and Technol. 38:280297.

Espanany A, Fallah S, Tadayyon A (2016) Seed priming improves seed germination and reduces oxidative stress in black cumin (Nigella sativa) in presence of cadmium. Ind Crops Prod. 79: 195-204.

Farahani HA, Moaveni P, Maroufi K (2011) Effect of hydropriming on seedling growth of basil (Ocimum basilicum L.). Adv Enironm Biol. 5:2258-2263

Heydecker W, Higgins J, Turner YJ (1975) Invigoration of seeds. Seed Sci Technol. 3:881-888.

Ibrahim EA (2016) Seed priming to alleviate salinity stress in germinating seeds. J Plant Physiol. 192:38-46.

Iqbal M, Ashraf M (2013) Gibberellic acid mediated induction of salt tolerance in wheat plants: Growth, ionic partitioning, photosynthesis, yield and hormonal homeostasis. Environ Exp Bot. 86:76-85

Jafar MZ, Farooq M, Cheema MA, Afzal I, Basra SMA, Wahid MA, Aziz T, Shahid M (2012) Improving the performance of wheat by seed priming under saline conditions. J Agr Crop Sci. 198:38-45.

Jisha KC, Vijayakumari K, Puthur JT (2013) Seed priming for abiotic stress tolerance: an overview. Acta Physiol Plant. 35:1381-1396.

Kamran M, Shahbaz M, Ashraf M, Akram NA (2009) Alleviation of drought-induced adverse effects in spring wheat (Triticum aestivum L.) using proline as pre-sowing seed treatment. Pak J Bot. 41:621-632.

Kibinza $S$ et al (2011). Catalase is a key enzyme in seed recovery from ageing during priming. Plant Sci. 181:309-315.

Li J, Yin LY, Jongsma MA, Wang CY (2011) Effects of light, hydropriming and abiotic stress on seed germination, and shoot and root growth of pyrethrum (Tanacetum cinerariifolium). Ind Crops and Prod. 34:1543-1549.

Liu N, Shen Y, Huang B (2015) Osmoregulants involved in osmotic adjustment for differential drought tolerance in different bentgrass genotypes. J Am Soc Hortic Sci. 140:605-
613.

McDonald MB (2000). Seed priming. In: Black M, Bewley JD (ed) Seed technology and its biological basis. Sheffield Academic Press, Sheffield.

Oliveira AB, Prisco JT, Enéas-Filho J, Gomes-Filho E (2010) Salinity effects on germination and establishment of sorghum seedlings from artificially aged and primed seeds. J New Seeds 11:399-411.

Oliveira AB, Gomes-Filho E, Enéas-Filho J, Prisco JT, Alencar NLM (2011a) Seed priming effects on growth, lipid peroxidation, and activity of ROS scavenging enzymes in $\mathrm{NaCl}$-stressed sorghum seedlings from aged seeds. J Plant Interact. 7:151-159.

Oliveira AB, Alencar NLM, Prisco JT, Gomes-Filho E (2011b) Accumulation of organic and inorganic solutes in $\mathrm{NaCl}-$ stressed sorghum seedlings from aged and primed seeds. Scient Agríc. 68:632-637.

Patanè C, Cavallaro V, Cosentino SL (2009) Germination and radicle growth in unprimed and primed seeds of sweet sorghum as affected by reduced water potential in $\mathrm{NaCl}$ at different temperatures. Indust Crops Produc. 30:1-8.

Pereira MD, Dias DCFS, Dias LAS, Araújo EF (2009) Primed carrot seeds performance under water and temperature stress. Scient Agric. 66:174-179.

Pérez-García F (2009) Germination characteristics and intrapopulation variation in carob (Ceratonia siliqua $\mathrm{L}$.) seeds. Span J Agric Res. 7:398-406.

Perveen S, Shahbaz M, Ashraf M (2011) Modulation in activities of antioxidant enzymes in salt stressed and non-stressed wheat (Triticum aestivum L.) plants raised from seed treated with triacontanol. Pak J Bot. 43:2463-2468.

Pukacka S, Ratajczak E (2007) Age-related biochemical changes during storage of beech (Fagus sylvatica L.) seeds. Seed Sci Res. 17:45-53.

Sveinsdóttir H, Yan F, Zhu Y, Peiter-Volk T, Schubert S (2009) Seed ageing-induced inhibition of germination and postgermination root growth is related to lower activity of plasma membrane $\mathrm{H}^{+}$-ATPase in maize roots. $\mathrm{J}$ Plant Phisiol. 166:128-135.

Ton J, Ent S, Hulten MHA, Pozo M, Oosten V, Loon LC, Mauch-Mani B, Turlings TCJ, Pieterse CMJ (2009) Priming as a mechanism behind induced resistance against pathogens, insects and abiotic stress. Int Org Biol Cont. 44:3-13.

Witzel K, Weidner A, Surabhi GK, Varshney GK, Buck-Sorlin GH, Börner A, Mock HP (2010) Comparative analysis of the grain proteome fraction in barley genotypes with contrasting salinity tolerance during germination. Plant Cell Environ. 33:211-222

Yagmur M, Kaydan D (2008) Alleviation of osmotic stress of water and salt in germination and seedling growth of triticale with seed priming treatments. Afr $\mathrm{J}$ of Biotechnol. 7:21562162.

Yamaguchi T, Blumwald E (2005) Developing salt-tolerant crop plants: challenges and opportunities. Tr in Plant Sci. 10:615620.

Zhang Q, Rue K (2012) Glycinebetaine seed priming improved osmotic and salinity tolerance in turfgrasses. Hortsci. 47:11711174 